\title{
VEGETATION CHANGES AND THE RELATIONSHIP WITH CLIMATE VARIABILITY IN THE UPPER AND MIDDLE REACHES OF THE NENJIANG RIVER BASIN, CHINA
}

\author{
F. Huang ${ }^{\mathrm{a}, *}$, D.H. Wen ${ }^{\mathrm{b}}$, P. Wang ${ }^{\mathrm{a}}$ \\ a School of Geographical Sciences, Northeast Normal University, Renmin Street, Changchun, China- joycehf@126.com, \\ wangp666@nenu.edu.cn \\ ${ }^{\mathrm{b}}$ Changchun Institute of Optics, Fine Mechanics and Physics, Chinese Academy of Science, Dong Nanhu Road, Changchun, China- \\ 563334610@qq.com
}

Commission VIII, WG VIII/8

KEY WORDS: Vegetation Dynamics, NDVI, Climate Variability, Correlation Analysis, Rescaled Range Analysis, SPOT VEGETATION, the Upper and Middle Reaches of the Nenjiang River

\begin{abstract}
:
To detect changes in vegetation is desirable for modeling and predicting interactions between land surface and atmosphere. Multitemporal series of SPOT VEGETATION NDVI dataset and meteorological data were integrated to interpret vegetation dynamics and the linkage with climate variations in the upper and middle reaches of the Nenjiang River Basin (NRB) from 1999 to 2010 using the correlation analysis and the rescaled range $(\mathrm{R} / \mathrm{S})$ analysis. The results demonstrate that annual NDVI increased slightly and $26.02 \%$ vegetation coverage of the study area significantly improved. The area of significantly decreased in vegetation cover took up $13.33 \%$ of the total land in spring. In autumn, $26.2 \%$ of the study area showed a significant vegetation increase. The improved activity of vegetation might reinforce in summer and autumn, while the decreasing tendency in spring might be persistent in the future. The yearly NDVI had significant positive linkages with precipitation and relative humidity. NDVI related significantly and negatively with temperature, sunshine hours and wind velocity, because they may have effects of increasing evapotranspiration and risk of drought and cold damage of vegetation. The variations of annual NDVI were much affected by summer temperature, relative humidity and sunshine duration in autumn and spring wind velocity. Seasonal NDVI decreased in parallel with elevated temperature, but there was no correlation between NDVI and precipitation. Spring temperature, relative humidity in summer and autumn contributed markedly to NDVI variations in the same season. The vegetation improving trend may induce by the warm-wetting climate in recent twelve years.
\end{abstract}

\section{INTRODUCTION}

Vegetation affects several processes such as water balance, latent and sensible heat fluxes and carbon cycle. Dynamic monitoring of vegetation provides vital information reflecting the trend of climate change due to the notable characteristics of both seasonal and interannual variations, which has become an important issue in global climate change research. Land surface conditions and variations can be efficiently characterized by using satellite remotely sensed data owing to wide spatial coverage and internal consistency of data sets (Eidenshink and Faundeen 1994; Kerr and Ostrovsky 2003). Time-series datasets of Normalized Difference Vegetation Index (NDVI) have been the most commonly used approach for the temporal analysis of land-surface and climate change. Various NDVI datasets have been widely applied to assess terrestrial vegetation vigor at regional and global scales during past decades (Lambin and Strahlers, 1994; Ludeke et al., 1996; Lambin, 1996; Piao and Fang, 2001; Zhou et al., 2001; Fang et al., 2003; Ma and Frank, 2006; Fensholt et al., 2009; Huang and Wang,2010; Amri et al., 2011; Sun et al., 2011; Schucknecht et al., 2013; Horion et al.,2014; Ivits et al.,2014; Du et al., 2016).

The Nenjiang River Basin (NRB) is a typical basin in Northern China (Wang et al., 2010). In the past a few decades, land surface condition changes resulting from urbanization, water project constructions and agricultural activities have been dramatic. After the disastrous flood in 1998, the deforestation gradually slowed down due to the implement of some ecological management policies. Previous studies focused on land use/cover changes in sub-area or the whole watershed region (Ye et al., 2001; Wang et al., 2010; Tang et al., 2012). The research on the dynamic of vegetation cover since the $21^{\text {st }}$ century and its relationship with climate factors is still lacking. The main purposes of this study are (1) to elaborate the interannual and seasonal variations in the coverage of vegetation in the upper and middle reaches of the Nenjiang River Basin (NRB), (2) analyze the possible causes of vegetation changes based on multitemporal NDVI, meteorological data for the period of 1999 to 2010. The result may offer scientific evidences for the land management and landscape ecological regulation in this region.

\section{STUDY AREA}

The Nenjiang River originates from the south foot of the Yilehuli Mountain in the Great Khingan Mountains. It flows south across the Khingan Mountains Area, Nenjiang County, Molidawa Banner, Nehe City, Gannan County, Fuyu County, Qiqihar City, Tailai County, Longjiang County, Zhalaite County and Zhaoyuan County and meets the Second Songhua River near Da'an County of Jilin Province to form the Songhua

* Corresponding author. 
River. The total length of the river is $1370 \mathrm{~km}$, with drainage area of $29.4 \times 10^{4} \mathrm{~km}^{2}$. The average runoff depth is $76.5 \mathrm{~mm}$ and the annual runoff is $227.3 \times 10^{8} \mathrm{~m}^{3}(\mathrm{Xu}, 2008)$. The main tributaries of Nenjiang River are Ganhe River, Namoer River, Nuomin River, Zhuoer River, Taoer River, etc. The upstream region (from the Greater Khingan Range to Nenjiang County) is hilly and mountainous area, mostly covered by forest. The midstream between Nenjiang County and Molidawa Banner is a transition region from hill to plain with relative flat terrain especially left bank. The Nenjiang River Basin locates in the temperate and monsoon climatic zone and has a typical continental climate. The annual average temperature is around $2-4^{\circ} \mathrm{C}$, and $\geq 10^{\circ} \mathrm{C}$ accumulated temperature is between $2600^{\circ} \mathrm{C}$ and $2850^{\circ} \mathrm{C}$. The average annual precipitation ranges from $470 \mathrm{~mm}$ to $500 \mathrm{~mm}$ in upstream and $400 \mathrm{~mm}$ to $460 \mathrm{~mm}$ in midstream area, respectively. The soil type in NRB is dominated by brown coniferous forest soil, dark brown forest soil, meadow soil (Eutric Vertisol, FAO), black soil (Luvic Phaeozem, FAO) chernozem (Haplic Chernozem, FAO) and swamp soil. The natural vegetation is mainly composed of the larch (Larix gmelimii), birch (Betula platyphylla), Mongolian pine (Pinus sylvestris var mongolica), red pine (Pinus koraiensis) and reed (phragmites communis).

\section{METHOD}

\subsection{Data and Processing}

The SPOT VEGETATION NDVI dataset (10-day synthesis product) was used in the study. The data has been processed and distributed at the Image Processing Center of VITO in Belgium (available from the VEGETATION website at http://www.vgt.vito.be/index.html). NDVI subsets for Southeast Asia $\left(68-147^{\circ} \mathrm{E}, 5-55^{\circ} \mathrm{N}\right)$ obtained from the VEGETATION website (http://www.vgt.vito.be/pages/policy.html) are 10-day MVC composites at a 1-km spatial resolution. In this study, 432 VGT-S10 images between January 1-10, 1999 and December 21-31, 2010 were subset for the upper and middle reaches of the Nenjiang River Basin. These temporal data were transformed and resampled using a nearest neighbour operator into the UTM projection based on WGS84 spheroid within ENVI 4.8 software. The simple formula, i.e. NDVI $=\mathrm{DN} \times 0.004-0.1$ was used to relate DNs to NDVI value within those images. NDVI values are within a range of $-1.0-1.0$. The annual average NDVI (ANDVI) was calculated through averaging monthly maximum NDVI, which provides information about the vegetation condition on the land surface. The maximum NDVI of month was calculated using Maximum Value Composites (MVC) method by maximizing the three stages of data. The average seasonal NDVI (SNDVI), namely spring (March to May), summer (June to August) and autumn (September to November) were also computed.

Meteorological data of eight meteorological stations in the study area were collected from China Meteorological Data Sharing Service System (http://data.cma.cn/). The adopted meteorological datasets included monthly averaged temperature, precipitation, relative humidity, sunshine duration, wind velocity from 1999 to 2010 . The average temperature, precipitation, relative humidity, sunshine duration, wind velocity of spring, summer, autumn and the whole year derived from these monthly data were computed for performing a correlation analysis with SNDVI and ANDVI data.

\subsection{Calculation of Annual and Seasonal NDVI}

The temporal evolution of decadal NDVI composition is regarded as an effective time window to show the natural seasonal variations, the consequences of extreme climatic events and the man-induced damage suffered by ecosystems. In the present study, the ANDVI and SNDVI values are applied to detect the inter-annual and seasonal variation of vegetation, which can be calculated using the equation (1):

$$
\overline{\operatorname{ANDVI}}=\frac{1}{n} \bullet \sum_{\mathrm{i}=1}^{n} \operatorname{ANDVI}_{i} \quad \overline{S N D V I}=\frac{1}{n} \bullet \sum_{\mathrm{j}=1}^{n} S N D V I_{j}
$$

where $n$ is the years range, $\mathrm{ANDVI}_{i}$ is the average NDVI value of year $i, \mathrm{SNDVI}_{j}$ represents average NDVI in season j. $\overline{A N D V I}$ and $\overline{S N D V I}$ is the average ANDVI and average SNDVI over the study period, respectively.

\subsection{Correlation Analysis}

The correlation analysis method provides the best results in terms of interpretation and showed a consistent measure of vegetation change, regardless of the study area and period (Herrmann et al., 2005; Cai and Yu, 2009). In the study, the spatial trend of ANDVI or SNDVI change in the upper and middle reaches of the Nenjiang River can be depicted from the following estimation:

$$
R_{x y}=\frac{\sum_{i=1}^{n}\left(x_{i}-\bar{x}\right)\left(y_{i}-\bar{y}\right)}{\sqrt{\sum_{i=1}^{n}\left(x_{i}-\bar{x}\right)^{2} \cdot \sum_{i=1}^{n}\left(y_{i}-\bar{y}\right)^{2}}}
$$

where $R_{x y}$ is the correlation coefficient for each pixel. $n$ is year range, $x_{i}$ is the year $i . y_{i}$ represents ANDVI or average NDVI in season $j$ of the year $i\left(\mathrm{SNDVI}_{j}\right), \bar{x}$ is the average of year range. $\bar{y}$ is the average ANDVI or average SNDVI over the study period, respectively. A positive value $\left(R_{x y}>0\right)$ depicts positive correlation suggesting that enhanced vegetation activity, whereas a negative correlation coefficient $\left(R_{x y}<0\right)$ indicates decreasing vegetation cover in the study period. $F$-statistics was used to determine the significance of the correlation analysis. Based on the $R_{x y}$ and significance threshold at $99 \%$ and $95 \%$, the change trends of ANDVI and SNDVI ${ }_{j}$ are classified into six types: (1) strongly significant decrease $\left(R_{x y}<0, \mathrm{P} \leq 0.01\right)$;(2) significant decrease $\left(R_{x y}<0,0.01<\mathrm{P} \leq 0.05\right)$; (3) insignificant decrease $\left(R_{x y}<0, \mathrm{P}>0.05\right)$; (4) insignificant increase $\left(R_{x y}>0\right.$, $\mathrm{P}>0.05)$; (5) significant increase $\left(R_{x y}>0,0.01<\mathrm{P} \leq 0.05\right)$; (6) strongly significant increase $\left(R_{x y}>0, \mathrm{P} \leq 0.01\right)$.

\subsection{Rescaled Range Analysis}

The phenomenon of persistence (extension of periods with systematic deviations from the long-term mean) is quantified by calculating the Hurst exponent $H$ (Hurst 1951) using the rescaled range or $R / S$ statistics (Mandelbrot and Wallis 1969). The Hurst exponent provides a measure for longterm memory and fractality of a time series. The values of the Hurst exponent range between 0 and 1 . A time series can be classified into three cases according to the Hurst exponent value $H$. (1) $\mathrm{H}=0.5$ indicates a random series. (2) $0<\mathrm{H}<0.5$ represents antipersistent behaviour. (3) $0.5<\mathrm{H}<1$ indicates a persistent series. An anti-persistent series has a characteristic of "mean- 
reverting", which means an up value is more likely followed by a down value, and vice versa. The strength of "mean-reverting" increases as $\mathrm{H}$ approaches 0 (Qian and Rasheed, 2004). A persistent series is trend reinforcing, which means the direction (up or down compared to the last value) of the next value is more likely to be followed by current value. The strength of trend increases as $\mathrm{H}$ approaches 1 . In this study, the Hurst exponents of ANDVI and SNDVI were calculated by rescaled range analysis ( $\mathrm{R} / \mathrm{S}$ analysis) to quantitatively characterize vegetation dynamics. For a time series, $\{\zeta(t)\}, \mathrm{t}=1,2,3, \ldots, \mathrm{N}$; taking a sub series $\tau=1,2,3, \ldots, \mathrm{N}$, the mean of $\tau$ is defined as:

$$
\langle\zeta\rangle_{\tau}=\frac{1}{\tau} \sum_{t=1}^{\tau} \xi(t)
$$

For the cumulative deviate at time $t$ of $\tau$,

$$
X(t, \tau)=\sum_{u=1}^{t}\left(\xi(u)-\langle\zeta\rangle_{\tau}\right), 1 \leq t \leq \tau
$$

The range series $R$ is calculated as follows:

$$
R(\tau)=\max \underset{1 \leq T \leq \tau}{X}(t, \tau)-\max \underset{1 \leq T \leq \tau}{X}(t, \tau)
$$

The standard deviation series $\mathrm{S}$ is determined by:

$$
S(\tau)=\sqrt{\frac{1}{\tau} \sum_{t=1}^{\tau}\left(\xi(t)-\langle\xi\rangle_{\tau}\right)^{2}}
$$

Rescaled range series $(\mathrm{R} / \mathrm{S})$ is calculated by dividing the range by the standard deviation. Hurst found that $(\mathrm{R} / \mathrm{S})$ scales by power-law as time increases, which indicates

$$
\frac{R(\tau)}{S(\tau)}=(c \tau)^{H}
$$

where $\mathrm{c}$ is a constant and $\mathrm{H}$ is called the Hurst exponent. The value of $\mathrm{H}$ is obtained using an ordinary least squares regression with $\log (\tau)$ as the independent variable and $\log (\mathrm{R}(\tau) / \mathrm{S}(\tau))$ as the dependant variable. The slope of the regression line approximates the Hurst exponent.

\section{RESULTS AND DISCUSSION}

\subsection{Temporal Change of NDVI}

The annual average NDVI slightly increased with an undulating trend in the upper and middle reaches of the NRB (Table 1). Wave crest of the ANDVI occurred in 2010, whereas the lowest trough found in 2004. Increased NDVI mean values from 2000 to 2002,2004 to 2007 and 2009 to 2010 indicated recovery of vegetation. Yearly NDVI decreased by $1.3 \%$ and $6.3 \%$ implying degraded vegetation cover during 1999-2001 and 2007-2009.

At the seasonal scale, vegetation was most vigorous in summer with the highest NDVI values ranging from 0.182 to 0.245 . NDVI in autumn came second between 0.111 and 0.146. In summer, regional average NDVI almost kept stable for the study period. NDVI in autumn increased by $5.93 \%$ between 1999 and 2010, whereas the spring NDVI decreased by $-6.45 \%$.

\begin{tabular}{|c|c|c|c|c|}
\hline Year & \multicolumn{4}{|c|}{ NDVI } \\
\hline 1999 & ANDVI & SNDVI $_{\text {spring }}$ & SNDVI $_{\text {summer }}$ & SNDVI $_{\text {autumn }}$ \\
2000 & 0.165 & 0.062 & 0.232 & 0.118 \\
2001 & 0.162 & 0.059 & 0.182 & 0.122 \\
2002 & 0.174 & 0.05 & 0.212 & 0.119 \\
2003 & 0.16 & 0.059 & 0.245 & 0.111 \\
2004 & 0.154 & 0.052 & 0.217 & 0.134 \\
2005 & 0.166 & 0.056 & 0.238 & 0.133 \\
2006 & 0.169 & 0.051 & 0.224 & 0.134 \\
2007 & 0.177 & 0.059 & 0.202 & 0.136 \\
2008 & 0.173 & 0.060 & 0.237 & 0.146 \\
2009 & 0.166 & 0.068 & 0.206 & 0.112 \\
2010 & 0.180 & 0.058 & 0.232 & 0.125 \\
\hline
\end{tabular}

Table 1. The annual and seasonal NDVI changes

\subsection{Spatial Change of Vegetation Cover}

Fig. 1 illustrates the spatial pattern of interannual ANDVI during past twelve years. The NDVI values approximately increased from south to north, which were consistent with the main types of land cover in the study area. ANDVI values greater than 0.50 overlapped with the distribution of dense forest. The values of multi-year average NDVI ranging from 0.38 to 0.50 were concentrated in the north indicating forestland and high to moderate density grassland. The places with ANDVI values of $0.26-0.38$ were dominated by cropland, some scattered grassland of high density and marshland. The regions with NDVI of 0.14-0.26 were occupied by water area and grassland of moderate density.

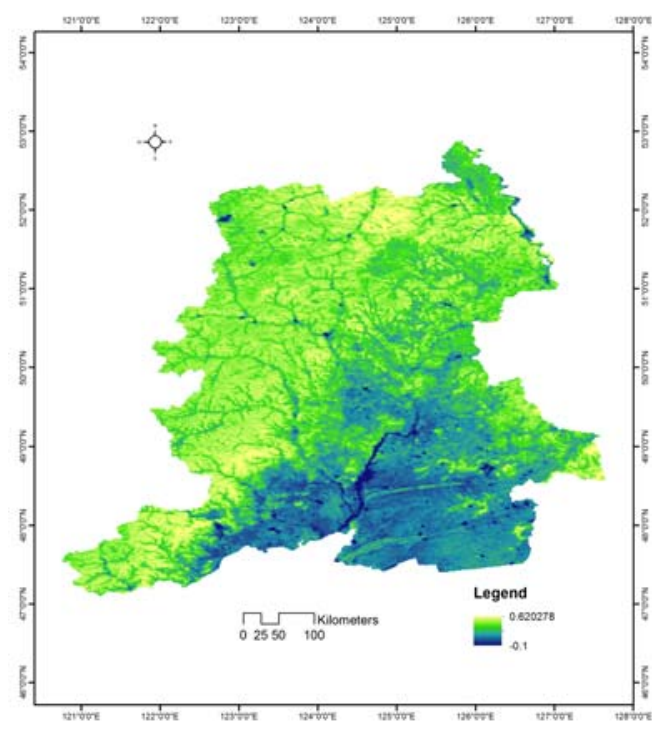

Figure 1. Spatial pattern of multi-year average NDVI

$26.02 \%$ of the study area showed a significant vegetation increase, while only $1.32 \%$ showed a significant decrease (Table 2). $72.66 \%$ of the study area in the south and north had no significant change trend. $10 \%$ of the upstream and middle 
stream regions, the ANDVI indicated a strong significant increase. The area where ANDVI significantly increased mainly distributed in Oroqen Autonomous Banner, the southeast Huma County, the north of Nenjiang County and the west of Zhalantun City (Fig. 2a). The significant decrease in vegetation cover was observed in the bording area between Huma County and Oroqen Autonomous Banner, Morin Dawa Daur Autonomous Banner and Nehe City. These results indicated that a large portion of the upper and middle reaches of the NRB had experienced a significant vegetation increase, and only a small part had significantly showed vegetation decrease in the past twelve years.

\begin{tabular}{|l|c|c|c|c|}
\hline $\begin{array}{l}\text { Vegetation } \\
\text { change trend }\end{array}$ & \multicolumn{4}{|c|}{ Area percentage (\%) } \\
\hline $\begin{array}{l}\text { Strongly } \\
\text { significant } \\
\text { increase } \\
\begin{array}{l}\text { Significant } \\
\text { increase }\end{array}\end{array}$ & 10.00 & 0.05 & 8.20 & 6.19 \\
$\begin{array}{l}\text { No significant } \\
\text { increase }\end{array}$ & 61.44 & 47.70 & 62.92 & 65.73 \\
$\begin{array}{l}\text { No significant } \\
\text { decrease } \\
\begin{array}{l}\text { Significant } \\
\text { decrease }\end{array}\end{array}$ & 11.22 & 37.98 & 2.49 & 7.56 \\
$\begin{array}{l}\text { Strongly } \\
\text { significant } \\
\text { decrease }\end{array}$ & 0.75 & 7.50 & 0.20 & 0.28 \\
\hline
\end{tabular}

Table 2. The area percentage of vegetation change trends
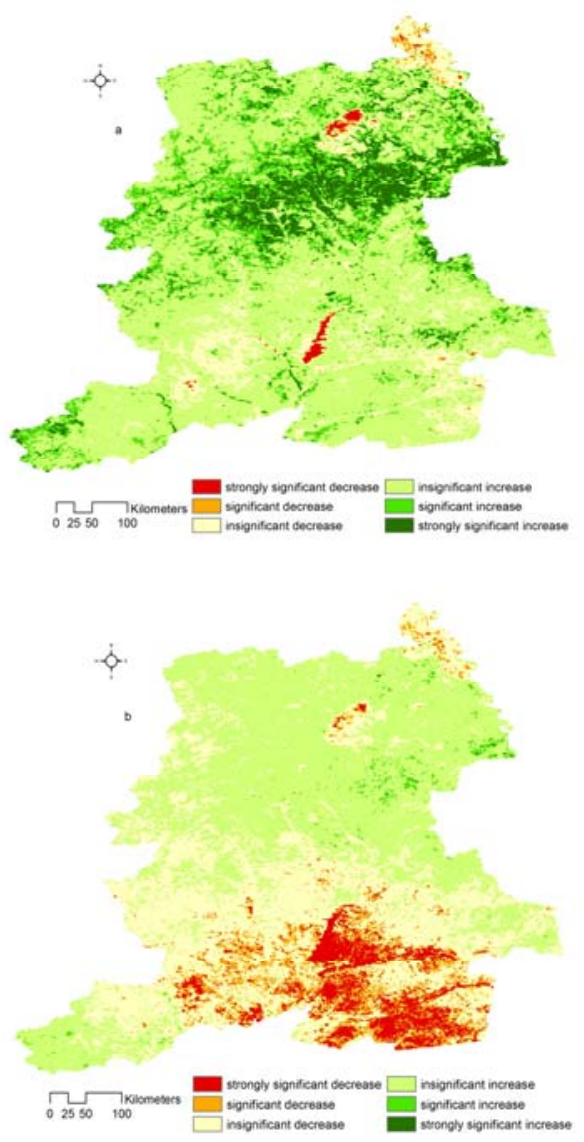
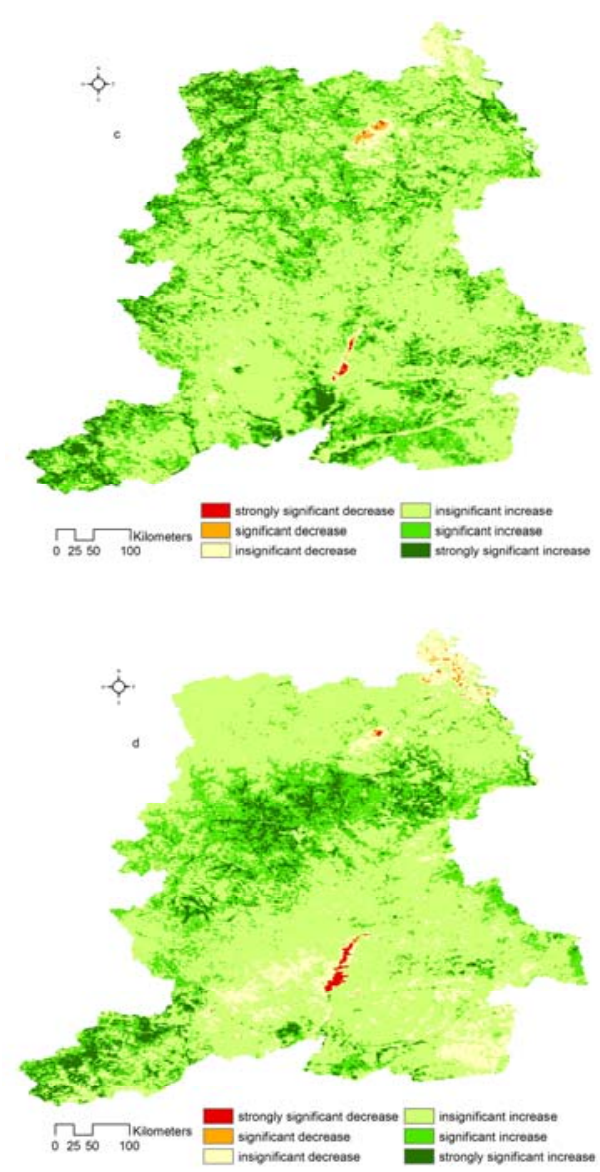

Figure 2. Spatial change of vegetation (a) total year (b) spring (c) summer (d) autumn

In spring from 1999 to 2010 , about $85.68 \%$ of the total area had no significant change trend. $13.33 \%$ of the study area showed a significant decrease, whereas $0.99 \%$ showed a significant vegetation increase. Most decreased vegetation cover in spring was observed in downstream region including Nehe City, Arong Banner, Morin Dawa Daur Autonomous Banner, Keshan County, Kedong County, Baiquan County, Wudalianchi City, Fuyu County, Gannan County,Yian County and Baiquan County(Fig. 2b). Some vegetation in the northeast of Oroqen Autonomous Banner and the southeast Huma County had significantly increase trend. Vegetation cover tended to increase significantly in summer probably owing to increasing agricultural crop production. The improved area occupied about $34.32 \%$ of the study area, mainly distributed in the west of Huma County, the north of Oroqen Autonomous Banner, the west of Zhalantun City, Keshan County, Fuyu County, Gannan County, Yian County and Baiquan County (Fig. 2c). Approximately $65.41 \%$ of the total area had no significant change trend in summer. The area of significantly decreased in vegetation cover took up $0.27 \%$ of the total land. In autumn, $26.2 \%$ of the study area showed a significant vegetation increase, and $0.51 \%$ decreased dramatically. Increasing vegetation cover was mostly found in most area of Oroqen Autonomous Banner and Zhalantun City (Fig. 2d). Except for spring, the vegetation activity in summer and autumn tended to improved. 


\subsection{Vegetation Behaviour Persistence}

The relationship between R/S value and time lag was illustrated in Figure 3, suggesting the linear trend in the log-log axes. The estimated Hurst exponents of the yearly NDVI and NDVI in different seasons were both greater than 0.5 suggesting that NDVI time series was persistent, that is, it was trend reinforcing. In general, the strength of trend increases as Hurst exponent approaches $1 . \mathrm{H}$ value of annual average NDVI in the study area was 0.6156. A rising tendency of ANDVI in the past twelve years will cause possible increase in the future. The persistence of the summer NDVI time series was more significant (0.9323), whereas the stability of vegetation growth in spring is lowest with Hurst exponent value of 0.5325 . Vegetation cover in the study area may keep improving in the future.

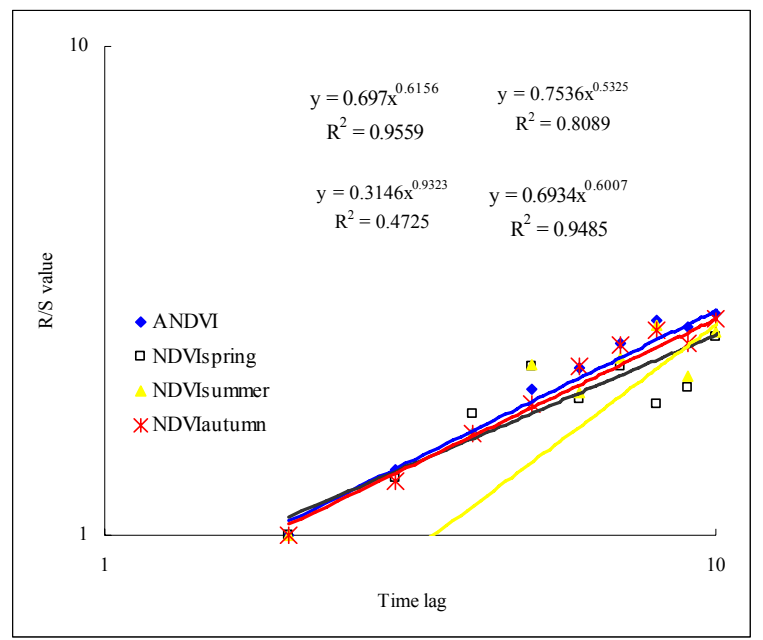

Figure 3. R/S analysis of ANDVI and seasonal NDVI between 1999 and 2010

\subsection{Relationship between Vegetation Change and Climate Factors}

During 1999-2010, the annual temperature and precipitation displayed an increasing trend at rates of $0.021^{\circ} \mathrm{C}$ and $8.401 \mathrm{~mm}$ per year respectively (Fig. 4). The warm-wet climate during the past twelve years may have impacts on the regional ecosystem. At seasonal scale, spring temperature kept steady while rainfall increases at rate of $0.229 \mathrm{~mm}$ per year (Fig.5). Summer precipitation increased at the rates of $6.134 \mathrm{~mm}$ per year, while temperature decreased slightly at rate of $-0.009^{\circ} \mathrm{C}$ per year over the study period. The raised pattern of temperature in autumn was observed with growth rates of $0.097^{\circ} \mathrm{C}$, whereas precipitation decreased $-0.946 \mathrm{~mm}$ per year. The climate in the study area showed a warmer and wetter trend in spring, but in summer, it showed a cooler and wetter trend. The warming and drying trend in autumn was observed.

Pearson correlation coefficients between NDVI variations and the climatic factor variations of total year in eight stations were calculated. The NDVI increased in parallel with elevated precipitation and air humidity. As shown in Table 3, the ANDVI had significant positive linkages with annual precipitation $(R=0.254, p=0.008)$ and average relative humidity $(R=0.417, p=0.000)$. Warmer temperature may have the effect of increasing evaporation and transpiration in vegetation, thus acting as a limiting factor (Hu et al. 2010).

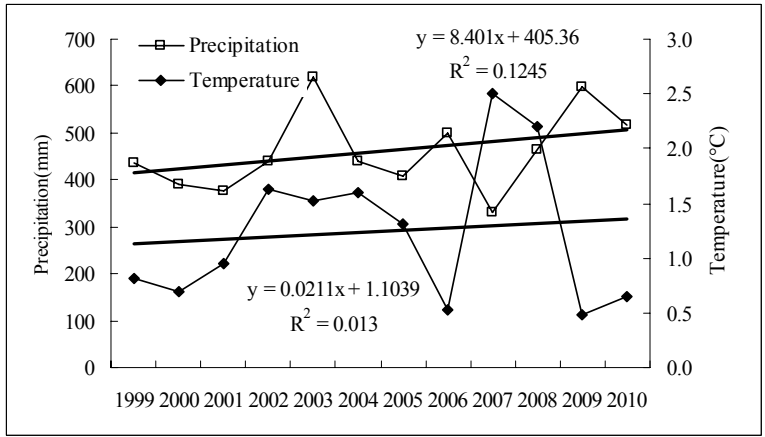

Figure 4. Changes in annual precipitation and temperature
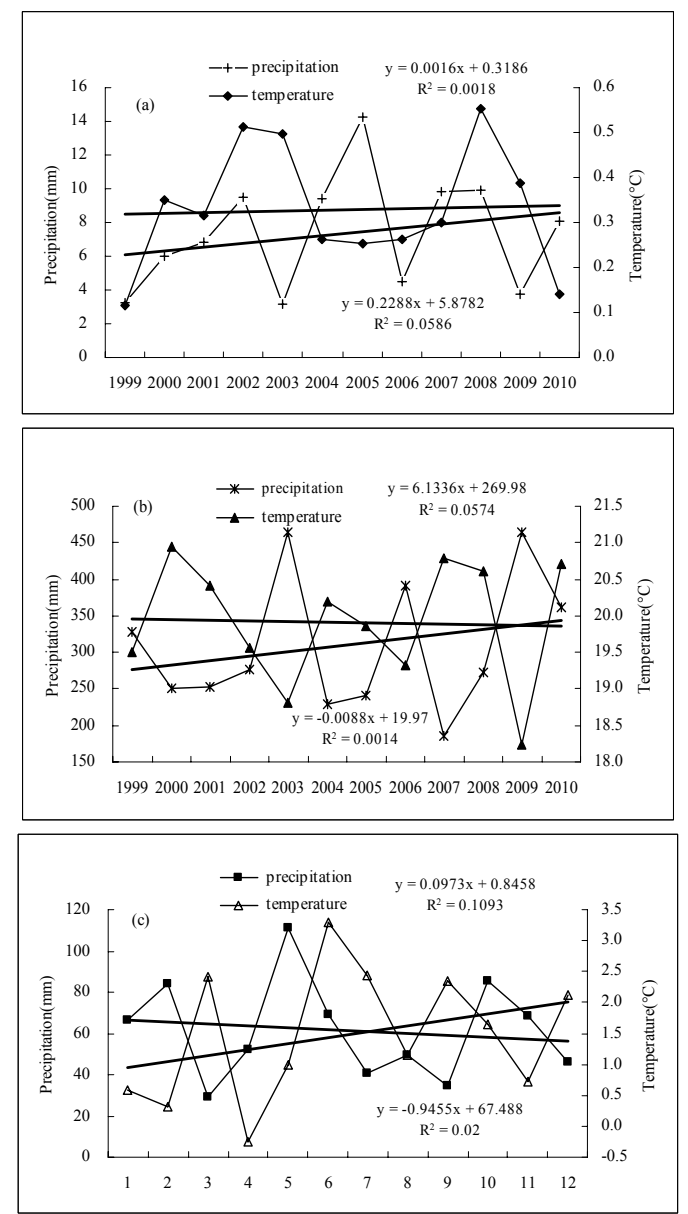

Figure 5. Variations of precipitation and temperature in spring (a), summer (b) and autumn(c)

Increasing sunshine duration may likewise cause increasing evapotranspiration and eventually decreasing NDVI. ANDVI related significantly and negatively with average temperature $(R=-0.426, p=0.000)$ and sunshine hours $(R=-0.338, p=0.000)$, respectively. Increasing wind velocity may also result in increasing surface evapotranspiration and loss of soil water, thereafter the drought and low temperature and cold damage of vegetation will aggravate. It was found that the annual mean NDVI showed a negative correlation with average wind $\operatorname{velocity}(R=-0.287, p=0.000)$. Compared to other season, the average temperature in summer had most significantly negative impact on ANDVI $(R=-0.405, p=0.000)$. Annual NDVI was significantly and positively related to average relative humidity in autumn $(R=0.412, p=0.000)$. Only precipitation in summer 
had significantly positive correlation with $\operatorname{ANDVI}(R=0.197$, $p=0.041$ ).

\begin{tabular}{|l|c|c|c|c|}
\hline $\begin{array}{l}\text { Climate } \\
\text { variables }\end{array}$ & \multicolumn{4}{|c|}{ Correlation coefficient (R) } \\
\hline Precipitation & Year & Spring & Summer & Autumn \\
$\begin{array}{l}\text { Average } \\
\text { temperature }\end{array}$ & $-0.254^{* *}$ & 0.06 & $0.197^{*}$ & 0.185 \\
$\begin{array}{l}\text { Average } \\
\text { relative } \\
\text { humidity }\end{array}$ & $0.417^{* *}$ & $-0.360^{* *}$ & $-0.405^{* *}$ & $-0.395^{* *}$ \\
$\begin{array}{l}\text { Sunshine } \\
\text { duration }\end{array}$ & $-0.338^{* *}$ & -0.149 & $-0.234^{*}$ & $-0.314^{* *}$ \\
$\begin{array}{l}\text { Average } \\
\text { wind velocity }\end{array}$ & $-0.287^{* *}$ & $-0.325^{* *}$ & $-0.311^{* *}$ & $-0.236^{*}$ \\
\hline
\end{tabular}

Table 3. The correlation coefficients between annual NDVI and climate variables $(* *$. Correlation is significant at the 0.01 level and $*$ represents at the 0.05 level (2-tailed). $n=108)$

\begin{tabular}{|l|c|c|c|}
\hline Climate variables & \multicolumn{3}{|c|}{ Correlation coefficient (R) } \\
\hline & Spring & Summer & Autumn \\
Precipitation & 0.021 & 0.133 & 0.106 \\
Average temperature & $-0.371 * *$ & $-0.322^{* *}$ & $-0.205^{*}$ \\
Average relative & 0.171 & $0.365^{* *}$ & $0.330^{* *}$ \\
humidity duration & -0.035 & -0.145 & $-0.204 *$ \\
Sunshine dut & & $-0.354^{* *}$ & -0.140 \\
\hline
\end{tabular}

Table 4 . The correlation coefficients between seasonal NDVI and climate variables $(* *$. Correlation is significant at the 0.01

level and * represents at the 0.05 level (2-tailed). $n=108$ )

Table 4 illustrates the correlation coefficients between mean NDVI and climatic variables in the same season. The significantly negative correlations were observed between average temperature and NDVI in spring $(R=-0.371, p=0.000)$, in summer $(R=-0.322, p=0.001)$ and in autumn $(R=-0.205$, $p=0.033)$, respectively. There existed no correlation between mean NDVI and precipitation in the same season. Higher relative humidity might help to increase moisture availability for plants, which had markedly positive impact on NDVI, especially in summer and autumn. Mean NDVI in summer showed a significantly negative correlation with wind velocity in summer $(R=-0.354, p=0.000)$.

\section{CONCLUSIONS}

Monitoring vegetation variations over time at regional to global scales and its response to climate change using Earth Observation data has greatly improved our understanding of the changing planet. In the present paper, SPOT-VGT datasets of NDVI were used to evaluate variations in vegetation productivity and their relationship with climate factors in the upper and middle reaches of the Nenjiang River Basin, China. The results demonstrate that annual NDVI increased slightly and $26.02 \%$ vegetation coverage of the study area significantly improved. Vegetation cover in spring months degraded, while the increase amplitude and trends of vegetation cover in summer and autumn were more noticeable. The computed Hurst exponents of NDVI values at annual and seasonal scale were greater than 0.5 , suggesting that the improved activity of vegetation might reinforce in summer, autumn and the whole year. However, the decreasing tendency of NDVI in spring would be persistent.

The warm-wet climate during the past twelve years may have impacts on the regional ecosystem. The yearly NDVI had significant positive linkages with precipitation and relative humidity. Precipitation in summer contributed obviously to increasing annual NDVI. Temperature and intense radiation may have the effect of increasing evaporation and transpiration in vegetation, thus NDVI related significantly and negatively with average temperature and sunshine hours, respectively. Increasing wind velocity may intensity the risk of drought and low temperature and cold damage of vegetation, and it showed a negative correlation with annual NDVI. The variations of annual NDVI were much affected by summer temperature, relative humidity and sunshine duration in autumn and spring wind velocity. At seasonal scale, the NDVI decreased in parallel with elevated temperature, but there was no correlation between mean NDVI and precipitation. Spring temperature, relative humidity in summer and autumn contributed obviously to changes of NDVI of the same season. The tendency of vegetation activity increased in the upper and middle reaches of the NRB from 1999 to 2010 in the whole.

\section{ACKNOWLEDGEMENTS}

The authors would like to acknowledge the Project 41571405 supported by National Natural Science Foundation of China.

\section{REFERENCES}

Amri R., Zribi M., Lili-Chabaane Z. Duchemin B. Gruhier C. \& Chehbouni A. 2011.Analysis of vegetation behavior in a North African semi-arid region, using SPOT-VEGETATION NDVI data. Remote Sensing, 3(12), pp.2568-2590.

Cai B.F. \& Yu R. 2009.Advance and evaluation in the long time series vegetation trends research based on remote sensing. Journal of Remote Sensing, 13(6), pp.1179-1176.

Du J.Q, Zhao C.X., Shu J.M. Ahati Jiaerheng, Yuan X. J., Yin J.Q. \& He P. 2016. Spatiotemporal changes of vegetation on the Tibetan Plateau and relationship to climatic variables during multiyear periods from 1982-2012, Environmental Earth Sciences, 75(1), pp.1-18

Eidenshink J.C. \&Faundeen J. L. 1994. The $1 \mathrm{~km}$ AVHRR global land data set: First stages in implementation. International Journal of Remote Sensing, 15(17), pp. 34433462 .

Fang J.Y., Piao S.L., He J.S. \& Ma W.H. 2003. Vegetation activity increasing in China in the past 20 years. Science in China (Series C), 33(6), pp.554-565.(in Chinese)

Fensholt R., Rasmussen K. Nielsen T.T. \& Mbow C. 2009. Evaluation of earth observation based long term vegetation trends-Intercomparing NDVI time series trend analysis consistency of Sahel from AVHRR GIMMS, Terra MODIS and SPOT VGT data. Remote Sensing of Environment, 113(9), pp.1886-18983.

Herrmann S. M., Anyamba A. \& Tucker C. J. 2005. Recent trends in vegetation dynamics in the African Sahel and their 
relationship to climate. Global Environmental Change Part A, 15(4), pp. 394-404.

Horion, S., Fensholt, R., Tagesson, T., \& Ehammer, A. 2014. Using earth observation based dry season NDVI trends for assessment of changes in tree cover in the Sahel. International Journal of Remote Sensing, 35(7), pp.2493-2515.

Hu M.Q., Mao F., Sun H., Hou Y.Y. 2010. Study of normalized difference vegetation index variation and its correlation with climate factors in the three-river-source region. International Journal of Applied Earth Observation and Geoinformation, 13(1), pp.24-33.

Huang F. \& Wang P. 2010. Vegetation change of ecotone in west of Northeast China Plain using time-series remote sensing Data. Chinese Geographical Science, 20(2), pp.167-175.

Ivits, E., Horion, S., Fensholt, R., \& Cherlet, M. 2014. Drought footprint on European ecosystems between 1999 and 2010 assessed by remotely sensed vegetation phenology and productivity. Global Change Biology, 20(2), pp.581-593.

Kerr J. T. \& Ostrovsky M. 2003. From space to species: Ecological applications for remote sensing. Trends in Ecology and Evolution, 18(3), pp.299-305.

Lambin E. F. \& Strahlers A. H. 1994. Change-vector analysis in multitemporal space: a tool to detect and categorize land cover change processes using high temporal-resolution satellite data. Remote Sensing of Environment, 48 (2), pp.231-244.

Lambin E. F.1996. Change detection at multiple temporal scales-seasonal and annual variations in landscape variables. Photogrammetric Engineering \& Remote Sensing, 62(8), pp.931-938.

Ludeke M. K. B., Ramge P. H. \& Kohlmaier G. H. 1996.The use of satellite NDVI data for the validation of global vegetation phenology models: application to the Frankfurt Biosphere Model. Ecological Modelling, 91(95), pp.255-270.

Ma M.G. \& Frank V. 2006.Interannual variability of vegetation cover in the Chinese Heihe River Basin and its relation to meteorological parameters. International Journal of Remote Sensing, 27(16), pp.3473-3486.

Mandelbrot B.B. \& Wallis R. 1969.Robustness of The Rescaled Range R/S in The Measurement of Noncyclic Long-Run Statistical Dependence, Water Resources Research, 5(5), pp.967-988

Piao S.L. \& Fang J.Y. 2001. Dynamic vegetation cover change over the last 18 years in China. Quaternary Sciences, 21(4), pp.294-302.

Qian, B. \& Rasheed, K., 2004. Hurst exponent and financial market predictability", In: IASTED Conference on Financial Engineering and Applications, (Ed.) Hamza, M.H., Vol. 437043 of FEA. Cambridge, UK.

Schucknecht, A., Erasmi, S., Niemeyer, I., \& Matschullat, J. 2013. Assessing vegetation variability and trends in northeastern Brazil using AVHRR and MODIS NDVI time series. European Journal of Remote Sensing, 46(1), pp.40-59.

Schucknecht, A., Erasmi, S., Niemeyer, I., \& Matschullat, J. 2013. Assessing vegetation variability and trends in north- eastern Brazil using AVHRR and MODIS NDVI time series. European Journal of Remote Sensing, 46(1), pp.40-59.

Sun J.Y., Wang X.H., Chen A.P., Ma Y.C. Cui M.D. \& Piao S. L. 2011. NDVI indicated characteristics of vegetation cover change in China's metropolises over the last three decades. Environmental Monitoring and Assessment, 179(1), pp.1-14.

Tang J.M., Bu K., Yang J.C., Zhang S.W. \& Chang L.P. 2012. Multitemporal analysis of forest fragmentation in the upstream region of the Nenjiang River Basin, Northeast China, Ecological Indicators ,23, pp. 597-607.

Wang S.H., Zhao Y.W., Yin X.A, Yu L. \& Xu F. 2010. Land use and landscape pattern changes in Nenjiang River basin during 1988-2002. Front. Earth Sci. China, 4(1), pp. 33-41.

$\mathrm{Xu}$ D.X. 2008. Runoff variation and it's impacting factor in Nenjiang River during 1956-2006. Dissertation of Master Degree, Northeast Institute of Geography and Agroecology, Chinese Academy of Sciences, Changchun, China.

Ye, B., Fang, H., Zhang, S. \& Zhang, Y. 2001. The driving forces of land use/cover change in the upstream area of the Nenjiang River. Chinese Geographical Science, 11(4), pp.377381 .

Zhou, L. M., Tucker, C. J., Kaufmann, R. K., Slayback, D., Shabanov, N. V. \& Myneni, R. B. 2001. Variations in northern vegetation activity inferred from satellite data of vegetation index during 1981 to 1999. Journal of Geophysical ResearchAtmospheres, 106(D17), pp.20069-20083.

Revised February 2016 